\title{
A Chinese commitment to commit: can it break the negotiation stall?
}

\author{
Valentina Bosetti · Carlo Carraro • Massimo Tavoni
}

Received: 28 July 2009 / Accepted: 13 September 2009 / Published online: 21 October 2009

(C) The Author(s) 2009. This article is published with open access at Springerlink.com

\begin{abstract}
Preparatory talks to the next round of negotiations seem to indicate that a comprehensive agreement to mitigate climate change will not be easily attainable, despite the intentions of the US administration and the high expectations surrounding the Copenhagen meeting. One key reason is to what extent fast growing economies, and especially China, should take actions to reduce their growth of emissions. This paper argues that a turning point for international negotiations on climate change could be achieved if China were to agree on carbon obligations in the future. Results from modelling work suggest that the optimal investment behaviour is to anticipate the implementation of a climate policy by roughly 10 years, and that thus future commitments - if credible-could lead to significantly earlier steps towards carbon mitigation. If fast growing economies, and foremost China, believe in the long term objective of global stabilization of carbon concentrations, it might be economically
\end{abstract}

This paper is part of the research work being carried out by the Sustainable Development Programme of the Fondazione Eni Enrico Mattei. The usual disclaimer applies.

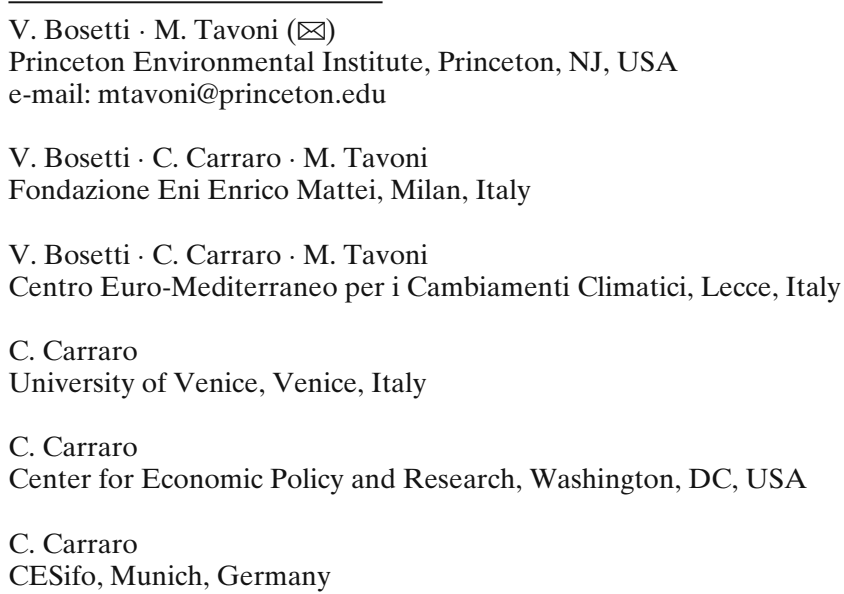


rationale to sign on future targets, provided developed countries take on immediate action. Such a provision could be beneficial for both the developing and developed world.

\section{Introduction}

During their most recent meeting in Italy, G8 countries have reiterated the commitment for taking rapid and effective global action to combat climate change. ${ }^{1}$ The representatives of the largest developed economies have recognized the need that the increase in global average temperature above preindustrial levels should not exceed $2^{\circ} \mathrm{C}$, and have supported a target of emissions reductions by developed countries of $80 \%$ by 2050 compared to recent years, and proposed a global objective of $50 \%$ by 2050 . Given that the current $\mathrm{CO}_{2}$ emissions from OECD and nonOECD countries are roughly equivalent, such a statement automatically implies that developing countries should aim at reducing their emissions by $20 \%$ with respect to current levels by the same time frame. ${ }^{2}$

This objective is however largely in contrast with the negotiating positions of essentially all emerging economies and least developed countries, which appeal to the large gaps in per capita emissions that divides the developed and developing countries, as well as to their different historical responsibilities. Such a diversity of positions suggests that the long standing logjam that has so far prevented the attainment of a wide ranging agreement in climate mitigation is still there, and that it might be hardly overcome by the strive for a post-2012 global agreement in Copenhagen. Yet, it is now accepted that a second best agreement with partial and delayed participation of developing countries would jeopardize its economic and environmental effectiveness (Bosetti et al. 2008; Edmonds et al. 2007; Keppo and Rao 2007; Clarke et al. 2009).

The changed attitude of the US administration has removed a long-standing obstacle, increasing the likelihood of concerted climate mitigation action from the major developed countries. Nonetheless, managing fast growing economies, China on top of the list, to get involved in the ultimate objective of climate stabilization will be the essential achievement of this and following rounds of negotiations. For example, despite the lower national averages, an increasingly large number of Chinese citizens are aiming at lifestyles and thus emissions similar to the ones of mature economies. According to Chakravarty et al. (2009), in 2030 China may have roughly 100 and 300 million people with per capita emissions equal or above today's US (20 t $\left.\mathrm{CO}_{2}\right)$ and $\mathrm{EU}\left(10 \mathrm{t} \mathrm{CO}_{2}\right)$ averages, respectively.

Such a dynamic process will require a progressive involvement of all major contributors to climate change. Countries in economic transition should act strategically since they are the ones where most of the investments are or will be made; thus, they should equip themselves with a stock of capital that can withstand the possibility of carbon regulation and meet the standard of the newly created markets for low carbon technologies. They should take on the opportunity to become innovators and move

\footnotetext{
${ }^{1}$ http://www.g8italia2009.it/static/G8_Allegato/MEF_Declarationl.pdf

${ }^{2}$ We thank Rob Socolow for first noticing this.
} 
to a more knowledge based economy. And they should be able to hedge against increasingly scarce resources such as fossil fuels, land and water.

In order to engage fast growing economies such as Brazil, Russia, India and China (the BRICs), many policies can be envisioned, such as international offsets, trade policies, technology and adaptation funds. This paper puts forward an additional suggestion. We argue that by committing now to future carbon obligations, fast growing countries would anticipate the adoption of energy and carbon efficiency measures and thus embark on an earlier mitigation pathway that could have positive repercussions for both the developed and developing world. This suggestion stems from the modelling results of Bosetti et al. $(2008,2009)$ in which policy anticipation is shown to have the potential to dominate leakage; investments in low carbon technologies and innovation are anticipated by roughly 10 years before the actual policy is implemented, to avoid the long lived energy capital stock to become inefficient when carbon is priced. Given its prominence in global emissions, its investment capacity and long term planning, China's commitment to future reductions could pave the way for a comprehensive climate deal.

This paper presents some results using WITCH, an energy-economy-climate model designed to evaluate climate change and energy policies. WITCH is an intertemporal optimization, regional model that has been widely used for the economic analysis of international climate policies. Its main distinguishing features include an in built representation of the energy sector into a macro-economic depiction of the economy, the modelling of technological evolution via diffusion and innovation processes related to both energy and carbon efficiency improvements, and a game theoretical set up that captures the strategic interaction of the various regions. This modelling framework allows us to account for various global externalities such as $\mathrm{CO}_{2}$, innovation market failures and overexploitation of finite natural resources. ${ }^{3}$

As an example, we examine the case of a long term stabilization goal of $550 \mathrm{ppm}$ $\mathrm{CO}_{2}$ equivalent. OECD countries are assumed to take on immediate (2015) commitment, whereas developing countries participation is graduated over time, with BRIC countries joining in 2030 and the rest of world in $2050 .{ }^{4}$ We compare two scenarios: a myopic one in which late participants stick to their BAU investments before joining the climate coalition, and a foresight one in which policy anticipation is allowed. In doing so, we are able to evaluate the implications of future obligations in terms of the transitional investments in energy and carbon efficiency. Many are the incentives to deviate from a baseline case, in both directions. A partial carbon policy could lead to international leakage through lower fossil fuel prices, delocalization of energy intensive industries and change in trade due to altered competitiveness. On the other hand, it could lead to lower emissions by creating new markets for low carbon technologies, by international technological and knowledge spillovers and by anticipation of future carbon prices in long lived investments. Through analysis carried out with an integrated assessment model, we suggest that the latter would dominate. Corroboration for this result can be found in the companion article by Blanford et al. (2009a).

\footnotetext{
${ }^{3}$ Full details about the model and related applications are accessible at the website www.feemweb.it/WITCH

${ }^{4}$ Although Russia already has an obligation under the Kyoto protocol, its association with the other major emerging economies reflects the uncertainty over its current and future climate policies.
} 

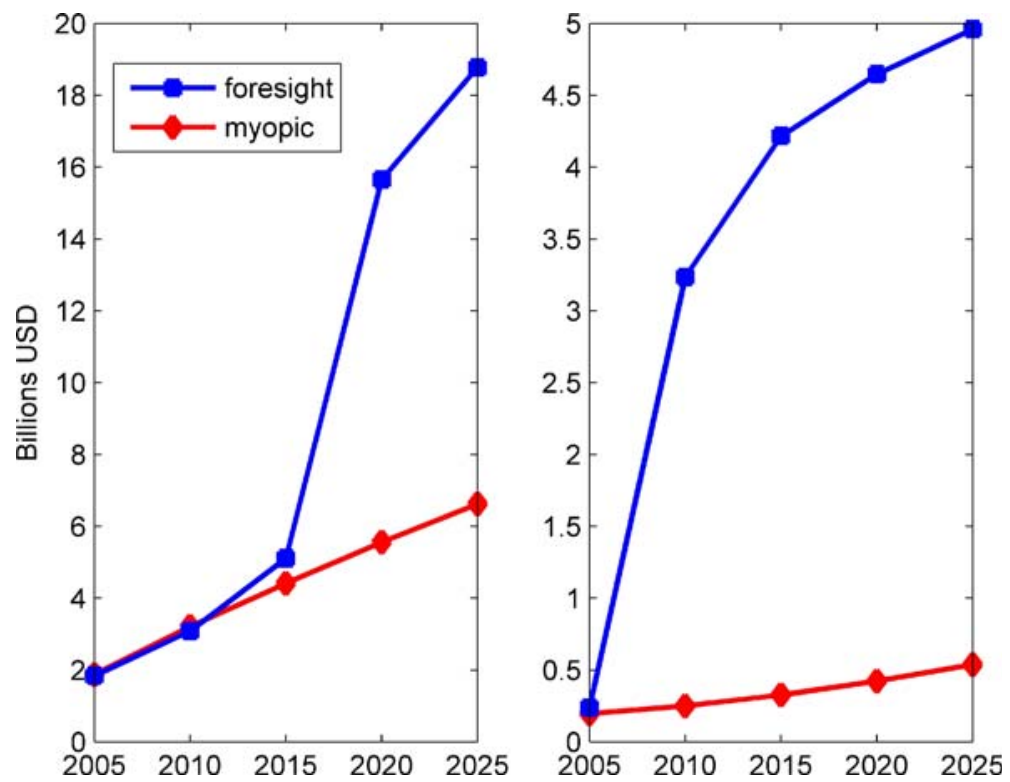

Fig. 1 Investments in China in nuclear power (left) and energy R\&D (right) before joining the climate coalition in 2030

\section{Optimal investment strategies when China takes on future obligations}

We investigate the implications of the agreement to start mitigation in 2030 on the transitional investments in low carbon options and innovation in China. ${ }^{5}$ Figure 1 shows that investments in nuclear power generation and public energy R\&D are anticipated as early as 2015, when the future target can be foreseen. In 2020, China invests three times as much in nuclear power plants as in the baseline and by 2030 it achieves roughly $70 \mathrm{GW}$ of nuclear power capacity, as opposed to $30 \mathrm{GW}$ in the myopic case. The surge in public energy R\&D investments, given the long commercialization lag times and the smaller investment amounts, starts even earlier, heading off baseline 15 years before. Investments in coal power plants without sequestration could proceed but should be eliminated after 2020 , by which year the transport sector should also begin to decarbonize. Electricity generation with carbon capture and storage (CCS) would be required later in time (2030), only at the time when China mitigation obligations really come into force.

The investment requirements envisaged by the commitment to commit are not incompatible with the objectives China has set for itself. For example, China has set a 2020 nuclear power target of $40 \mathrm{GW}$, and officials are now claiming that this objective may be exceeded by $50 \%$, reaching $60 \mathrm{GW}$ by $2020 .{ }^{6}$ It is also aiming at becoming a global technological and scientific powerhouse, with a total R\&D spending target

\footnotetext{
${ }^{5}$ China is a separate region in the model and we can thus present specific results for this BRIC country.

${ }^{6}$ http://www.reuters.com/article/rbssConsumerGoodsAndRetailNews/idUSL0868760220080308
} 
Fig. 2 Energy related carbon emissions in China to 2030

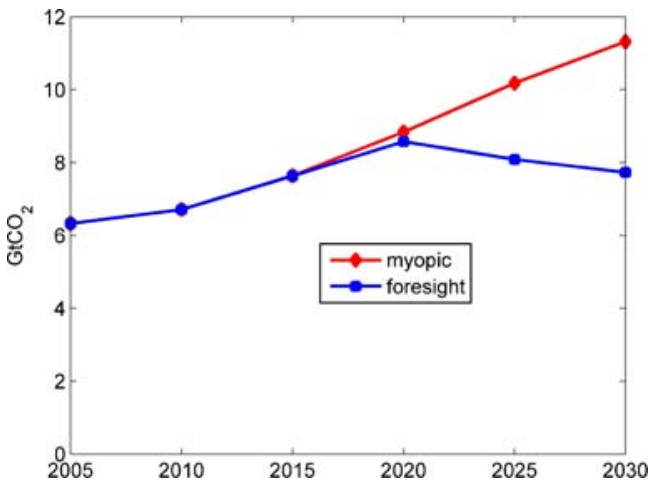

of $2.5 \%$ of GDP by 2020 . Most recently, China has allocated considerably resources (221 billion USD) to the green recovery of the financial crisis, twice as much as the US did (Robins et al. 2009).

The investment patterns indicate that policy anticipation could prompt early action in a major emerging economy such as China. Such a deviation from baseline would materialize in earlier mitigation of $\mathrm{CO}_{2}$ emissions, by roughly 10 years as shown in Fig. 2. ${ }^{7}$ Emissions would level off after 2020. A similar result can be found in Blanford et al. (2009b).

\section{The economic benefits of early action}

The mitigation effort of BRIC countries due to policy anticipation would give the OECD countries some additional abatement headroom, with understandable benefits in terms of reduced policy costs. Interestingly, we find that emerging economies could also benefit from an anticipation strategy.

Table 1 shows that the efficiency gains of policy anticipation-calculated as the relative difference in policy costs between the foresight and myopic cases-can be positive both globally and regionally. The global costs of stabilizing concentrations at $550 \mathrm{ppm} \mathrm{CO}_{2}$ equivalent would be reduced by $40 \%$ with respect to a case in which latecomers followed a myopic baseline strategy. The OECD countries have the most to gain by such a deal, that would allow them to halve their policy costs, which would otherwise be high had they to take on full mitigation responsibility to 2030. Nonetheless, both the BRIC and the rest of the developing countries would see their climate bill reduced by roughly $1 / 4$, a non negligible saving.

This is because capital build up that is optimized for the future policies would be better suited to bear carbon pricing and would trigger additional technological change. Given the many inertias that characterize the way energy is produced and consumed, this could lead to lower macroeconomic impacts of capital replacement and reallocation, and to lower global carbon prices due to higher innovation and better experience.

\footnotetext{
${ }^{7}$ Obviously, increasing the inertia with which energy capital can be replaced beyond the values assumed in the model would further stretch the anticipation period.
} 
Table 1 Reduction of global and regional macro-economic costs of climate policy due to policy anticipation (costs calculated as net present value losses of Gross World Product at a 5\% discount rate)

\begin{tabular}{ll}
\hline Region & Efficiency gains of policy anticipation \\
\hline World & $38 \%$ \\
OECD & $48 \%$ \\
BRICs & $22 \%$ \\
Other DC & $22 \%$ \\
\hline
\end{tabular}

It should be noted, however, that carbon price harmonization could eventually impose higher absolute costs to carbon intensive economies in developed and mostly developing countries. Participation incentives might be provided to alleviate part of this burden, for example through an international carbon market. Recognizing emission reductions below fast growing economies' optimal policy foresight strategy (and not their baseline) could encourage their accession without implying excessively large financial transfers from developed countries.

\section{Policy ahead}

Achieving a comprehensive international climate treaty will be a hard task given the many incentives to free ride on this global issue. The next rounds of UNFCCC meetings might not determine the solution but can prepare the ground for a negotiation process that might be revised periodically for many years. Several policy instruments should be used to gradually engage the most important countries into the global effort of mitigating climate change, keeping in mind the need for an economically sound solution.

This article has quantified the implications of fast growing economies commitment to future emission reduction obligations and has suggested that it could lead to significant benefits in terms of carbon abatement, technological innovation and economic efficiency. The investment requirements to comply with such a deal are likely manageable by China, a country that holds 2 USD Trillions of foreign exchange reserves. Indeed, several proposed national policies are compatible with such a future obligation. Ideally, the involvement of China could foster an escalate out of the current negotiation stall.

Such a strategy could be rational for the fastest growing economies as well, that would build up a less carbon intensive capital stock and could master technological change. It could also be complemented by some international offsets provision to create additional accession incentives.

Open Access This article is distributed under the terms of the Creative Commons Attribution Noncommercial License which permits any noncommercial use, distribution, and reproduction in any medium, provided the original author(s) and source are credited.

\section{References}

Blanford G, Richels R, Rutherford T (2009a) International climate policy: a "second best" solution for a "second best" world? Climatic Change Letters (forthcoming)

Blanford G, Richels R, Rutherford T (2009b) Feasible climate targets: the roles of economic growth, coalition development and expectations. Energy Econ. doi:10.1016/j.eneco.2009.06.003 
Bosetti V, Carraro C, Tavoni M (2008) Delayed participation of developing countries to climate agreements: should action in the EU and US be postponed? Fondazione Eni Enrico Mattei, Working Paper N.70-2008

Bosetti V, Carraro C, Tavoni M (2009) Climate change mitigation strategies in fast-growing countries: the benefits of early action. Energy Econ. doi:10.1016/j.eneco.2009.06.011

Chakravarty S, Chikkatur A, de Conink H, Pacala S, Socolow R, Tavoni M (2009) Sharing global $\mathrm{CO}_{2}$ emission reduction among one billion high emitters. Proc Natl Acad Sci USA 106(29):11884-11888

Clarke L, Edmonds J, Krey V, Richels R, Rose S, Tavoni M (2009) International climate policy architectures: overview of the EMF 22 international scenarios. Energy Econ (in press)

Edmonds J, Clarke L, Lurz J, Wise M (2007) Stabilizing $\mathrm{CO}_{2}$ concentrations with incomplete international cooperation. PNNL working paper

Keppo I, Rao S (2007) International climate regimes: effects of delayed participation. Technol Forecast Soc Change 74(7):962-979

Robins N, Clover R, Singh C (2009) A climate for recovery: the colour of stimulus goes green. HSBC Global Research 